\title{
Yeast Opsonisation and Complement in Children with Liver Disease. Analysis of 69 Cases
}

\author{
V. F. LARCHER, ${ }^{(30)}$ R. J. WYKE, D. VERGANI, A. P. MOWAT, AND ROGER WILLIAMS \\ Departments of Child Health, Immunology and the Liver Unit at King's College Hospital, London, Great Britain
}

\begin{abstract}
Summary
Opsonisation of heat-killed bakers yeast and $\mathrm{C} 3$ and $\mathrm{C} 4$ concentrations were determined in sera from 69 children with liver disease and 39 controls as simple screening procedures for abnormalities in the complement system. Where significant defects in these moieties were encountered, the activity of the following was measured: total haemolytic complement, $\mathrm{C4}, \mathrm{C5}$, total alternative pathway, factor $B$ and $D$ activities were measured. Complement activation was detected by the presence of C3d in EDTA plasma samples.

Yeast opsonisation, $\mathrm{C} 3$ and $\mathrm{C} 4$ concentrations and activities of all complement components measured were significantly $(P<$ $0.001)$ reduced in all of 10 children with fulminant hepatic failure (FHF) and six with chronic active hepatitis (CAH). There was no consistent relationship between complement deficiency and standard tests of liver function. $\mathrm{C} 3$ breakdown products were identified in plasma from five patients with $\mathrm{CAH}$ and complement deficiency but not in three patients with complement deficiencies associated with FHF. Complement concentration and activity improved in children recovering from FHF and in CAH treated by immunosuppressants.

Yeast opsonisation index was raised significantly without parallel increase in $\mathrm{C} 3$ or $\mathrm{C} 4$ concentration in eight of nine children with biliary atresia before surgery and 11 of 13 with alpha-1antitrypsin deficiency regardless of age or the presence of active liver disease. Yeast opsonisation indices became normal after successful surgery in patients with biliary atresia.
\end{abstract}

\section{Abbreviations}

CAH, chronic active hepatitis

CH50, total haemolytic complement

C3d, C3 breakdown products

EHBA, extrahepatic biliary atresia

FHF, fulminant hepatic failure

INH, idiopathic neonatal hepatitis

RID, radial immunodiffusion

TAP, total alternative pathway

Adults with liver disease have an increased incidence of infection $(8)$ in which deficiencies in host-defence mechanisms have been implicated (6). Patients with primary complement deficiency states have an increased incidence of infection $(1,3)$ and severe defects of complement occur in adults with liver disease $(9,10$, 28). Defective opsonisation of heat-killed bakers yeast, due to a specific defect in the alternative pathway of complement (23) that occurs in 5\% of normal children (13), is also associated with an increase incidence of infection (22) and has been reported in adults with acute liver disease (28).

Similar studies on children with liver disease, in whom the pattern and pathogenesis of this disease often differs from that in adults (15), have not been reported. In this paper we describe the results of measuring yeast opsonisation indices, $\mathrm{C} 3$ and $\mathrm{C} 4$ concentrations in sera of 69 children with acute and chronic liver disease. Where deficiencies of these factors were found, functional activity of complement components were measured to determine the extent and mechanism of the deficiency.

\section{PATIENTS AND METHODS}

The 69 children were aged between 6 weeks and 17 years. The types of liver disease are shown in Table 1. Diagnosis was confirmed histologically with or without other specific tests, for example, alpha-1-antitrypsin phenotyping in each case. Thirtythree patients had neonatal hepatitis syndrome, defined as obstructive jaundice in an infant under 4 months of age (16). Our patients included nine patients with biliary atresia tested before surgery and five studied only postoperatively, as well as 19 infants with idiopathic neonatal hepatitis. Sequential studies were performed on four children with biliary atresia. They were also performed on two children who had recovered from fulminant hepatic failure and two with chronic active hepatitis.

Our study included 39 controls aged from 8 weeks to 15 years of which 10 were infants aged between 8 weeks and 4 months to match the ages of infants with the neonatal hepatitis syndrome. All were in- or out-patients without history of liver disease, allergy, or infection in whom venepuncture was necessary as part of their management. The 10 control infants were comprised of seven patients undergoing a variety of surgical procedures, including herniorraphy and pyloroplasty and three patients admitted for observation because of non-accidental injury. The 29 older children underwent either cold surgical procedures or had encopresis or enuresis and were referred to the outpatients service. Venous blood for complement and opsonisation studies was allowed to clot at room temperature. Serum was separated within $3 \mathrm{~h}$, stored in aliquots at $-70^{\circ} \mathrm{C}$, and thawed once before use.

Yeast opsonisation was measured by the method described by Soothill and Harvey (22). Heat-killed bakers yeast was mixed with a suspension of normal polymorphonuclear leucocytes in a $2.5 \%$ concentration of test serum in stoppered plastic tubes and incubated on a rotary mixer at $37^{\circ} \mathrm{C}$ for $30 \mathrm{~min}$. The tubes were centrifuged for $5 \mathrm{~min}$ at $50 \times \mathrm{g}$ and the pellet resuspended in one drop of saline. A spread drop was dried on a slide and stained with May-Grunwald Giemsa stain. The numbers of yeasts in each of 100 unselected polymorphs was recorded $(0-7$ and $>7)$. The results are expressed as an opsonisation index, being the mean number of yeast particles phagocytosed per polymorph. Duplicate tubes were set up on each occasion and sera from healthy and known defective patients included in each assay. The mean opsonisation index for the 39 controls was $4.0 \pm 0.6 \mathrm{~S}$.D. (Fig. 1). In two of the controls (5\%), the range was less than 2.5 , which has been previously reported as defective (22). Opsonisation indices for sera from the 10 infants aged between 8 weeks and 4 months did not differ significantly $(\mathrm{t}=1.69, P>0.1)$ from that for the older children with opsonisation indices of 4.3 and 3.9 , respectively.

Serum concentrations of $\mathrm{C} 3$ and $\mathrm{C} 4$ were measured by radial immunodiffusion (RID system plates ICL Scientific Ltd.) and results expressed as \% of normal human serum used as a control. 
The mean serum concentrations of $\mathrm{C} 3$ and $\mathrm{C} 4$ for the controls was $130 \pm 25$ S.D. mg/dl (Fig. 2) and $26 \pm 6.2$ S.D. mg/dl (Fig. 3 ) respectively. These values represent $108 \pm 21 \%$ S.D. of a control pool of healthy adults for C3 and $92 \pm 23 \%$ S.D. for C4. These differences were not statistically significant and none of the controls had deficiency of either factor when measured functionally. When defects of yeast opsonisation, $\mathrm{C} 3$ and $\mathrm{C} 4$ were encountered, functional assays of $\mathrm{CH} 50, \mathrm{C} 4, \mathrm{C} 5$, TAP, factors $\mathrm{B}$ and $\mathrm{D}$ were performed using radial haemolytic diffusion assays $(11,14)$. Results were expressed as a \% of control serum pool, which was

\section{Table 1. Categories of patients}

\begin{tabular}{lc}
\hline \multicolumn{1}{c}{ Diagnosis } & Numbers \\
\hline Fulminant hepatic failure (acute stage) & 10 \\
Fulminant hepatic failure (recovered) & 2 \\
Chronic active hepatitis & 11 \\
Neonatal Hepatitis Syndrome & \\
Biliary atresia (preoperative) & 9 \\
Biliary atresia (postoperative) & 5 \\
Idiopathic neonatal hepatitis & 19 \\
Alpha-1 antitrypsin deficiency & 13 \\
& 69 \\
\hline
\end{tabular}

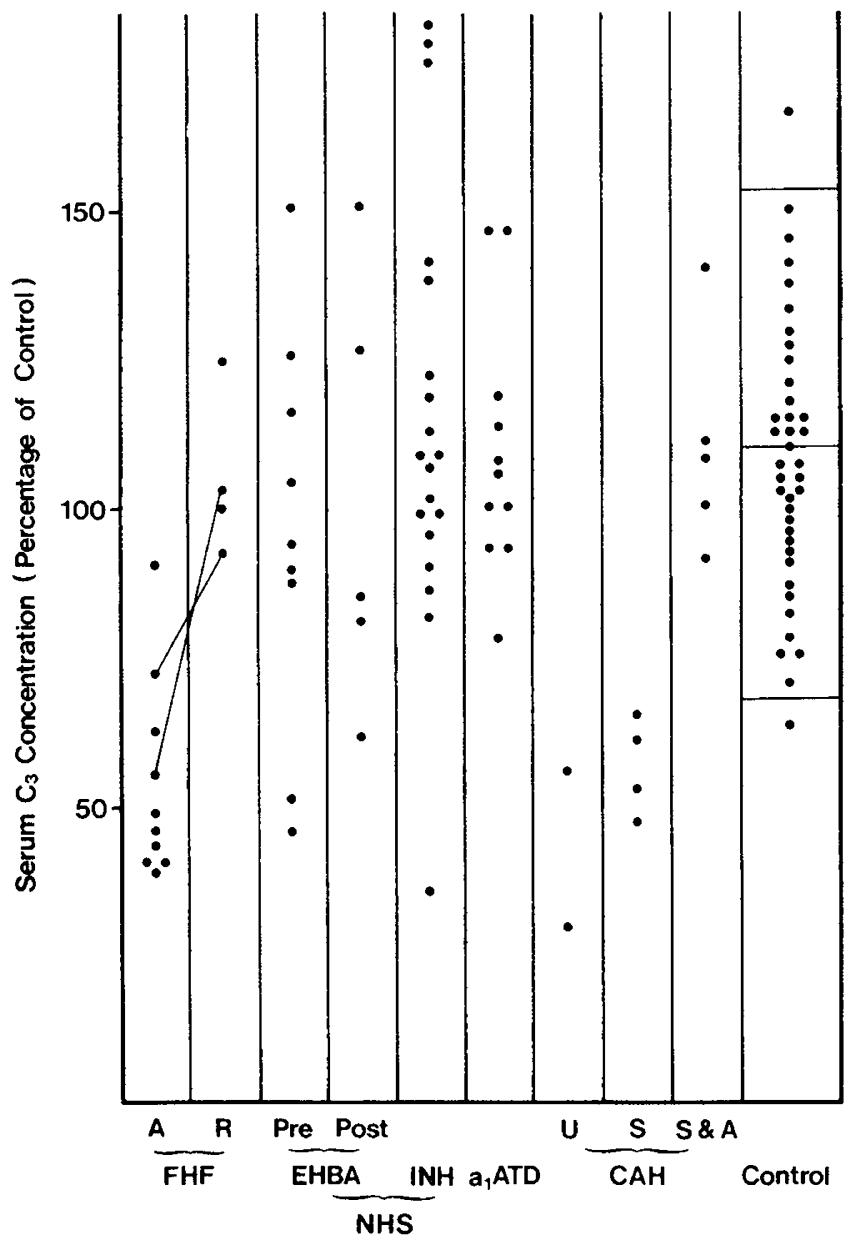

Fig. 1. Yeast opsonisation index (number of yeasts per polymorphonuclear neutrophil leucocyte) in 69 children with liver disease and 39 aged-matched children. Key: FHF, fulminant hepatic failure; A, acute illness; R, recovered patients; NHS, neonatal hepatitis syndrome; EHBA, extrahepatic biliary atresia; Pre, preoperative patients; Post, postoperative patients; INH, idiopathic neonatal hepatitis; $\alpha$-1-ATD, alpha-I antitrypsin deficiency; $\mathrm{CAH}$, chronic active hepatitis; $\mathrm{U}$, untreated, i.e., before treatment; S, steroid treatment; and S + A, steroids and azathioprine treated. The horizontal lines indicate mean \pm 2 S.D. for the controls.

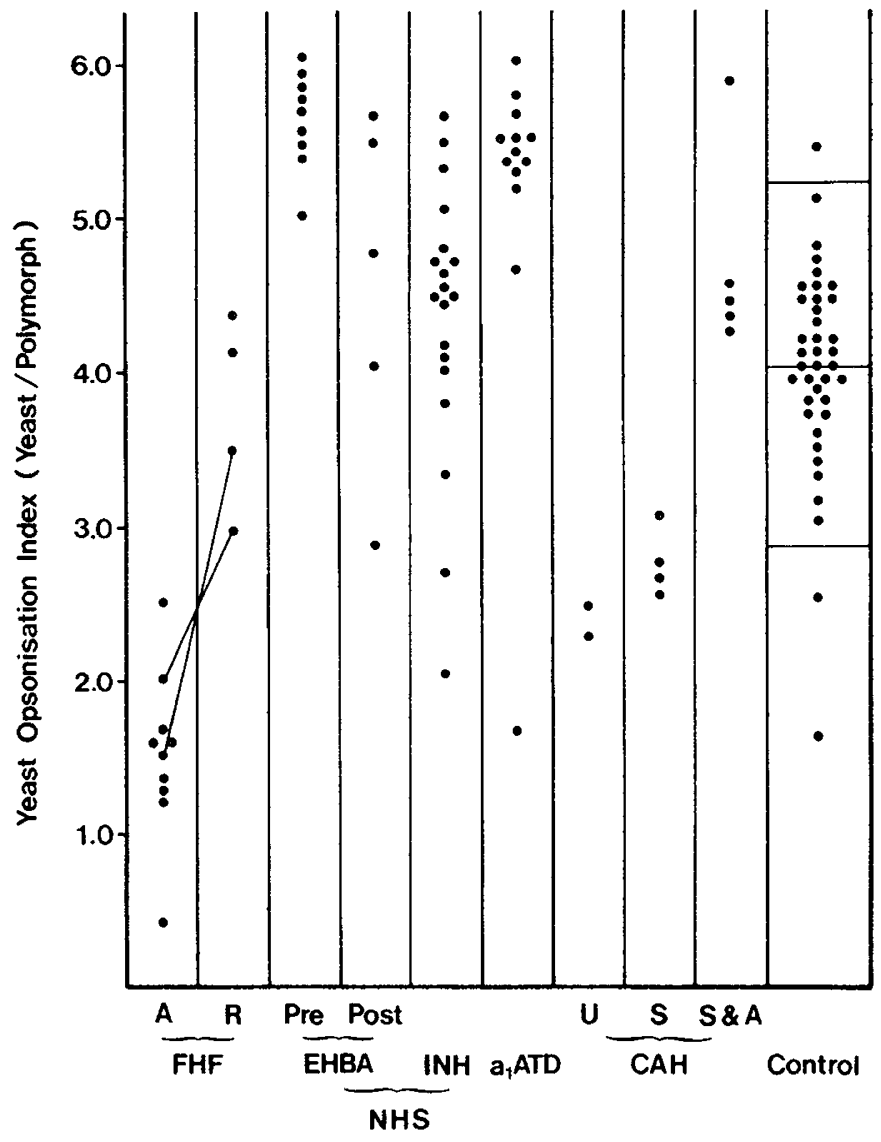

Fig. 2. Serum C3 concentration expressed as a $\%$ of human serum pool. Key as for Figure 1. Mean \pm 2 S.D. of control values shown.

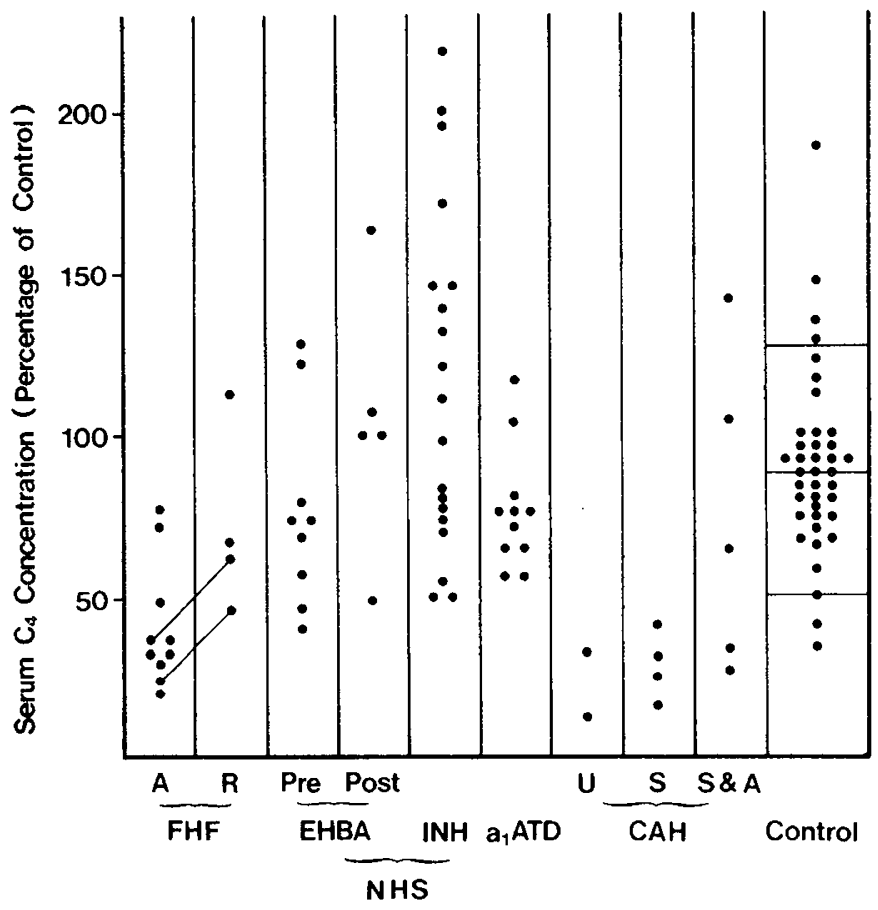

Fig. 3. Serum C4 concentration expressed as \% of normal human serum pool. Key as for Figure 1 Means and 2. S.D. of control values shown.

included in each assay. Values for all complement components assayed in control children did not differ significantly from those for adult controls.

Evidence of complement activation was sought by measurement 
of C3d (17) in samples of fresh EDTA plasma collected from some of the patients with complement deficiency. Levels of C3d exceeding 2 S.D. of control mean (i.e., $>0.7 \mathrm{mg} / \mathrm{ml}$ ) were taken to be significantly elevated.

Serum bilirubin, aspartate aminotransferase, alkaline phosphatase, albumin and prothrombin time were all measured by standard techniques. Data from groups were compared by Student's $t$ test. Relationships between data were derived by calculation of correlation coefficients.

\section{RESULTS}

$F H F$. Yeast opsonisation was defective in the 10 patients studied: the mean opsonisation index $(1.6 \pm 0.6$ S.D. $)$ being significantly reduced $(t=-11.2, P<0.001)$ compared with that for controls (4.0 \pm 0.6 S.D.) (Fig. 1). There was a significant inverse correlation $(r=-0.7, P<0.05)$ between opsonisation index and serum bilirubin. Levels of C3 and C4 were also reduced $(t=7.48$, 6.5 respectively, $P<0.001$ ) with a mean of $52 \pm 16 \%$ S.D. and 39 $\pm 20 \%$ S.D., respectively. Functional activity of CH50 and (TAP), C4, C5, factors B and D were each significantly $(P<0.001)$ reduced to less than $45 \%$ of control (Table 2 ) but C3d was not detectable in EDTA plasma samples obtained from three of the children.

When two of the children with FHF were re-investigated less than 2 months later, at a time when liver function was normal, opsonisation and C3 concentration had risen to normal (Figs. 1 and 2), $\mathrm{C} 4$ was low in one patient, and at the lower limit of normal in the other (Fig. 3). Opsonisation and complement components were also normal in two other survivors studied a year after their episode of fulminant hepatic failure (Table 2).

$C A H$. Two children with Hepatitis B surface antigen negative $\mathrm{CAH}$, studied at presentation before treatment with immunosuppressive drugs, had significant reduction of opsonisation indices (Fig. 1) and concentrations of C3 (Fig. 2) and C4 (Fig. 3). These changes were accompanied by significant reductions in $\mathrm{CH} 50$, TAP, C4, and C5 and Factor B activities to less than $25 \%$ of control (Table 2).

Of the four patients on long-term corticosteroid therapy, the opsonisation index was reduced in three and was at the lower limit of normal in one patient (Fig. 1); C3 was reduced in the same three (Fig. 2); and C4 was low in all four (Fig. 3). Mean functional activity of complement components in these patients (Table 2) was less than $50 \%$ of control and C3d was elevated (mean $1.3 \mathrm{mg}$ / $\mathrm{ml}$ ) in EDTA plasma samples obtained from each of the three patients examined. None had normal liver function. In five children treated with corticosteroids and azathioprine, yeast opsonisation and $\mathrm{C} 3$ were within the normal range (Figs. 1 and 2 ) whilst $\mathrm{C} 4$ was normal in three but reduced in two $(26,32 \%$ respectively; Fig. 3).

The two patients with reduced immunochemical $\mathrm{C} 4$ also had low functional activity of $\mathrm{C} 4$, reduced $\mathrm{CH} 50$, and their plasma contained increased concentrations of C $3 \mathrm{~d}(1.6,1.5 \mathrm{mg} / \mathrm{ml})$. Both children had biochemic and immunologic (increased serum immunoglobulin and tissue autoantibodies) evidence of continuing disease activity. In two separate patients studied sequentially, opsonisation and complement components measured functionally and immunochemically increased during the course of immunosuppressive treatment.

Table 2. Functional activity of complement components expressed as \% of control (mean \pm S.D.) in patients with fulminant hepatic failure (FHF) and chronic active hepatitis (CAH)

\begin{tabular}{|c|c|c|c|c|c|c|c|}
\hline Patient group & No. & $\mathrm{CH} 50$ & $\mathrm{C} 4$ & $\mathrm{C} 5$ & $\begin{array}{c}\text { Total alternative } \\
\text { pathway }\end{array}$ & $\mathrm{B}$ & $\mathrm{D}$ \\
\hline \multicolumn{8}{|l|}{ FHF } \\
\hline In coma & 10 & $36 \pm 34$ & $36 \pm 27$ & $31 \pm 15$ & $32 \pm 26$ & $40 \pm 29$ & $41 \pm 31$ \\
\hline Recovered & 4 & $120 \pm 44$ & $128 \pm 43$ & $124 \pm 22$ & $126 \pm 22$ & $120 \pm 40$ & $150 \pm 70$ \\
\hline \multicolumn{8}{|l|}{$\mathrm{CAH}$} \\
\hline Before treatment & 2 & 7 & 10 & 10 & 10 & 25 & \\
\hline Steroids alone & 4 & $33 \pm 11.5$ & $34 \pm 8.6$ & $50 \pm 14$ & $35 \pm 10.7$ & $40 \pm 32$ & \\
\hline Steroids + azathioprine & 5 & $74 \pm 15.3$ & $82 \pm 35$ & $82.5 \pm 43$ & $75 \pm 17$ & $120 \pm 24$ & \\
\hline
\end{tabular}

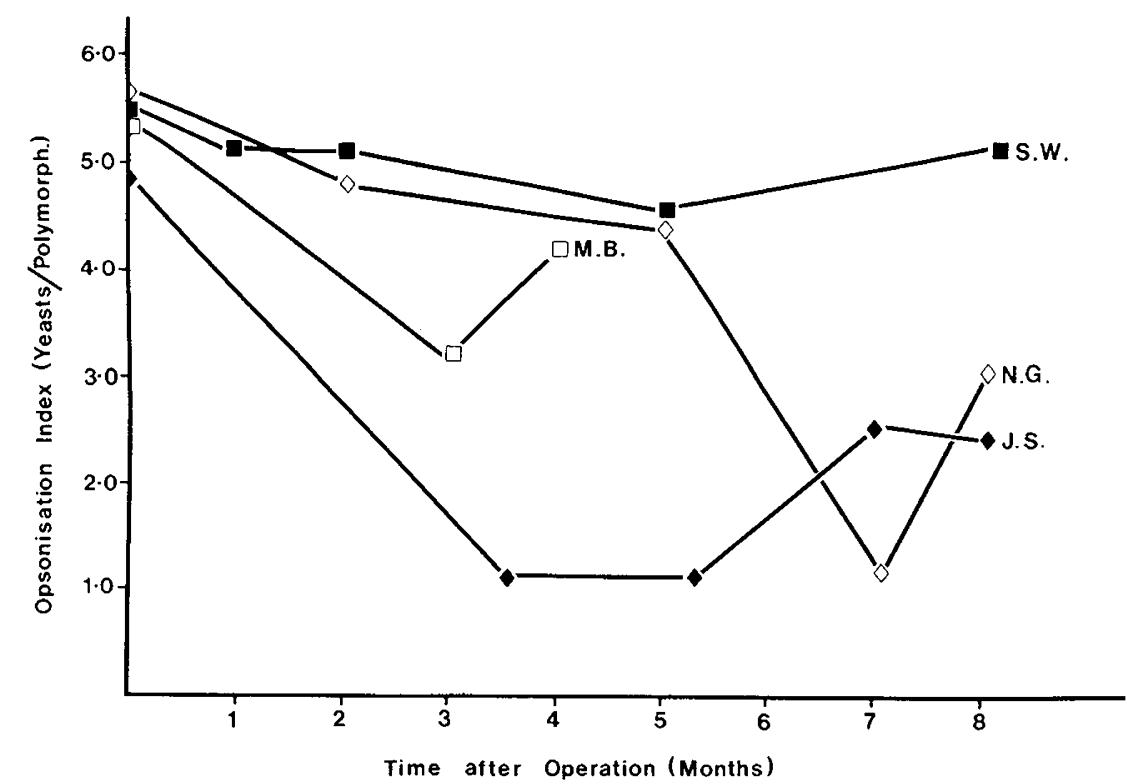

Fig. 4. Sequential estimation of yeast opsonisation index in four patients with extrahepatic biliary atresia subjected to porto-enterostomy to promote biliary drainage. Preoperative values shown at time 0 (see text for details). 
NEONATAL HEPATITIS SYNDROME

Idiopathic neonatal hepatitis (INH). In patients with INH, the yeast opsonisation index ( $4.32 \pm 0.75$ S.D.) did not differ significantly from that of the controls $(t=1.27 P>0.1$; Fig. 1$)$. Two infants with histologic features of severe hepatitis had opsonisation indices in the defective range (2.0 and 2.1, respectively). One of these two infants had reduction of $\mathrm{C} 3$ and functional deficiency of all complement components measured. Mean levels of serum C3 (116 $\pm 42 \%$ S.D.) and C4 (114 $\pm 53 \%$ S.D.) for the whole group were not significantly increased $(t=1.23,1.1$, respectively, $P>0.1$ ) when compared with controls (Figs. 2 and 3 ). Increased concentrations of C3 $(>152 \%)$ occurred in three patients and of $\mathrm{C} 4(>138 \%)$ in eight (Figs. 2 and 3 ). In addition, there was a significant $(r=0.9, P<0.01)$ correlation between $\mathrm{C} 3$ and $\mathrm{C} 4$ concentrations. There was a significant positive correlation $(r=$ $0.91,0.90$ respectively, $P<0.01$ ) between yeast opsonisation and levels of $\mathrm{C} 3$ and $\mathrm{C} 4$ and a significant inverse correlation $(r=$ $-0.94, P<0.01)$ between yeast opsonisation and prolongation of prothrombin time.

Extrahepatic biliary atresia $(E H B A)$. Yeast opsonisation index (mean 5.57, S.D. 0.35) was significantly increased in children with EHBA before surgery when compared with both age-matched controls $(t=-6.96, P<0.001)$ or patients with idiopathic neonatal hepatitis $(t=6.2 P<0.001$; Fig. 1). Two children had low levels of $\mathrm{C} 3$ (Fig. 2) and one child had low levels of C4 (Fig. 3) but the means for the whole group, $97 \pm 32 \%$ S.D. for C3 and $86 \pm 35 \%$ S.D. for C4, did not differ significantly from controls or infants with idiopathic neonatal hepatitis.

Opsonisation indices were also measured sequentially during the postoperative period in four children in whom a biliary drainage procedure (hepatic porto-enterostomy, Kasai operation) was performed. Of the two patients (N.G. and J.S., Fig. 4) in whom biliary drainage was considered on clinical and biochemical grounds to be adequate, the opsonisation index became normal in one and defective in the other, whereas the opsonisation index remained elevated in the other two (S.W. and M.B., Fig. 4) in whom biliary drainage was inadequate. Sera from five other children with EHBA and satisfactory bile drainage, who were examined post-operatively but not pre-operatively, had normal opsonisation indices (Fig. 1) and C3 and C4 (Figs. 2 and 3).

Alpha-1 antitrypsin deficiency. The opsonisation index was significantly increased in 12 of 13 patients with alpha-1 antitrypsin deficiency. The mean opsonisation index $(5.38 \pm 0.35$ S.D. $)$ was significantly raised $(t=7.95, P<0.001)$ in children with alpha-1 antitrypsin deficiency irrespective of clinical or biochemic evidence of active liver disease. Serum C3 and C4 levels were normal in all patients.

\section{DISCUSSION}

The deficiencies in yeast opsonisation and complement in children with FHF and CAH were of a similar order to those reported in adults with FHF (28) and in primary complement deficiency states $(1,3,23)$. These defects were unlikely to have been solely a function of the patients age because normal age-matched controls had levels of complement components and activity which did not differ significantly from those in published adult series $(9,10,22$, 28). Whilst there is an increased incidence of both opsonisation deficiency (19) and complement activation (24) in young, and especially preterm infants, none of the children studied were of similar age or gestation to these groups. It is also unlikely that the defects were primary or congenital because they were multiple, reversible and unassociated with previous symptoms suggesting opsonisation or complement deficiency $(1,3,23)$. Secondary defects in complement can be produced by failure of synthesis or excessive consumption of components and both have been implicated as a cause of complement deficiency in adults with liver disease $(9,10,28)$. Attempts to discriminate between these two mechanisms have been made, either by identification of complement activation products (17) or the use of turnover studies using radiolabeled complement components (26).
There is widespread destruction in FHF of both hepatocytes and nonparenchymal cells (5). Because both may synthesise complement (4), defective synthesis is perhaps the most likely explanation of the complement deficiency found in children with FHF. Failure to detect increased levels of $\mathrm{C} 3$ activation products $(\mathrm{C} 3 \mathrm{~d})$ in the presence of low levels of C3 in EDTA plasma from three children in the present series and in adults with FHF (VerganiUnpublished) suggests that complement consumption is not a major feature. Comparative $\mathrm{C} 3$ and albumin turnover studies have also suggested that poor synthesis of $\mathrm{C} 3$ is responsible for low levels seen in adults with severe acute hepatitis (26). But complement activation cannot be excluded entirely as the cause of complement deficiency because endotoxin and immune complexes, both capable of activating complement (7), are found in the sera of some patients with FHF $(12,27)$.

Interpretation of data derived from the present series suggests that increased consumption of complement is the major mechanism responsible for complement deficiency in CAH because $\mathrm{C} 3 \mathrm{~d}$ could be identified in all of the five plasma samples obtained from patients with concurrent complement deficiency. The presence of immune complexes, capable of consuming complement, in these sera (25) and more rapid turnover of C3 compared with albumin in adults with $\mathrm{CAH}(26)$ would also favour this view. The low functional and immunochemical levels of $\mathrm{C} 4$ seen in some treated patients with active liver disease in the present study might imply that complement-mediated liver damage was occurring. Yeast opsonisation and functional and immunochemical levels of complement components improved in patients treated with immunosuppressants. Those patients treated with steroids and azathioprine had higher levels than those treated with steroids alone; however, both of these groups usually received treatment for longer periods so that interpretation of this data is difficult.

The complement deficient states present in FHF and CAH contrasted with the significantly increased opsonisation indices found concomitantly with normal levels of $\mathrm{C} 3$ and $\mathrm{C} 4$ in patients with both biliary atresia before surgery and alpha- 1 antitrypsin deficiency regardless of age or presence of active liver disease. Only one patient with EHBA had a normal opsonisation index before surgery and this fell into the defective range after surgery. His mother also had defective opsonisation (23) suggesting that he had an underlying primary deficiency state as may occur in 5\% of the normal population (13).

The diagnostic value of measuring opsonisation indices to discriminate between biliary atresia and idiopathic neonatal hepatitis was limited by overlap which occurred in values obtained from these patients. Possible explanations for the high opsonisation indices found in biliary atresia before surgery include: (1) the behaviour of the factor responsible for yeast opsonisation as an acute phase protein (21) (2) a variation of the normal pattern observed in young infants (19); (3) failure of biliary excretion of the factor responsible (as may occur with respect to secretory IgA (18)); and (4) increased synthesis of factors of the alternative pathway of complement after increased consumption during chronic inflammatory processes (20). Because high opsonisation indices also occurred in patients with alpha-1 antitrypsin deficiency irrespective of age, degree of cholestatis or presence of elevated $\mathrm{C} 3$ or $\mathrm{C} 4$ levels, it is tempting to speculate that increased opsonisation in these conditions may have been related to the presence of chronic inflammation of the patient's inability to modulate it, as may occur in alpha-1 antitrypsin deficiency.

The practical importance of opsonisation and complement defects, whatever their pathogenesis, is their association with infection and an increased incidence of infection has been reported in FHF (29). The natural susceptibility of patients with CAH to infection is more difficult to assess because such patients are treated with immunosuppressants, which increase this susceptibility; however, two children under our care with poorly controlled CAH and defects of opsonisation and complement have subsequently developed three episodes of spontaneous bacterial peritonitis. Plasma infusions correct opsonisation deficiency (23) and may be of therapeutic value in patients with protracted diarrhoea 
(2). The role of plasma infusion in the treatment of complement deficiency associated with liver disease however, remains to be established.

The complement abnormalities reported here may have a role in the pathogenesis of the complications of liver disease, especially in infection. Their role in the pathogenesis of liver disease itself is more conjectural but certain aspects, for example the relationship between yeast opsonisation and the factors of the alternative pathway and chronic inflammation are worthy of further study.

\section{REFERENCES AND NOTES}

1. Alper, C. A., Colten, H. R., Rosen, F. S., Rabson, A. R., Macnab, G. M., and Geer, J. S. S.: Homozygous deficiency of $\mathrm{C} 3$ in a patient with repeated infections. Lancet, 2: 1179 (1972).

2. Candy, D. C. A., Larcher, V. F., Tripp, J. H., Harries, J. T., Harvey, B. A. M. and Soothill, J. F.: Defective yeast opsonisation in children with chronic diarrhoea. Arch. Dis. Child., 55: 189 (1980).

3. Clarke, R. A. and Klebanoff, S. J.: The role of the classical and alternative pathways in chemotaxis and opsonisation; studies of human serum deficient in C4. J. Immunol., 120: 1102 (1978).

4. Colten, H. R.: Development of host defences. The complement and Properdin system. In Cooper and Drayton, editors. Development of Host Defences. p. 165 (Raven Press, New York 1977)

5. Gazzard, B. G., Portmann, B., Murray-Lyon, I. H., and Williams, R.: Causes of death in fulminant hepatic failure in relationship to qualitative assessment of parenchymal liver cell damage. Quarterly J. of Med., 176: 615 (1975).

6. Gerding, D. N., Khan, M. Y., Ewing, J. W., and Hall, W. H.: Pasturella multocida peritonitis in hepatic cirrhosis with ascites. Gastroenterology, 70: 311 (1976).

7. Johnston, R. B. and Stroud, R. M.: Complement and host defence against infection. J. Pediatr., 90: 169 (1977).

8. Jones, E. A., Crowley, N., and Sherlock, S.: Bacteraemia in association with hepatocellular and hepatobiliary disease. Postgrad. Med. J., 43: 7 (Suppl.) (1967)

9. Kosmidis, J. C. and Leader-Williams, L. K.: Complement levels in acute infectious hepatitis and serum hepatitis. Clin. Exp. Immunol, 11: 31 (1972)

10. Kourilsky, O., Leroy, C., and Peltier, A. P.: Complement and liver cell function in 53 patients with liver disease. Am. J. Med., 55: 783 (1973)

11. Lachman, P. J., Hobart, M. J., and Aston, W. P.: Complement technology in: Weir, D. M., Ed. Handbook of Experimental Immunology, p. 7. (Blackwell Oxford 1973).

12. Larcher, V. F., Vergani, D., and Mowat, A. P.: Circulating immune complexes in children with fulminant hepatic failure and renal failure. Arch. Dis. Child., 55: $616(1980)$.

13. Levinsky, R. J., Harvey, B. A. M., and Paleja, S.: A rapid objective method for measuring yeast opsonisation in serum. J. Immunol. Methods, 24: 251 (1978).

14. Martin, A.. Lachman, P. J., Halbwachs, L., and Hobart, M. J.: Haemolytic diffusion plate assay for Factors $B$ and $D$ of the alternative pathway of complement activation. Immunochemistry, 13: 317 (1976).

15. Mowat, A. P.: Liver Disease in Infants and Children. In A. D. Bouchier, Ed., in Gastroenterology, No. 3 pages 261-296. (Churchill Livingstone, Edinburgh, London, New York 1976).

16. Mowat, A. P., Psacharopoulos, H. T., and Williams, R.: Extrahepatic biliary atresia versus neonatal hepatitis. A review of 137 prospectively investigated infants. Arch. Dis. Child., 51: 763 (1976).

17. Perrin, L., Lambert, P. H., and Miescher, P. A.: Complement breakdown products in plasma from patients with systemic lupus erythematosus and patients with membranoproliferative or other glomerulonephritis. J. Clin. Invest., 56: 165 (1975).

18. Renston, R. H., Jones, A. L., Christanson, W. D., and Hradek, G. T.: Evidence for a vesicular transport mechanism in hepatocytes for biliary secretion of immunoglobulin A. Science, 208: 1276 (1980).

19. Richardson, V. F., Larcher, V. F., and Price, J. F.: Yeast opsonisation in newborn infants and its relationship to parental atopy. Clin. Exp. Immunol., 48: 411 (1982).

20. Schorlemmer, H. U., Edwards, J. H., Davies, P., and Allison, A. C.: Macrophage responses to mouldy hay dust, micropolyspora faemi and Zymosan activators of complement of the alternative pathway. Clin. Exp. Immunol., 27: 198 (1977)

21. Shutte, M., Dicamelli, R., Murphy, P., Sadovi, M., and Gewurz, H.: C3 proactivators (C3 PA) as an acute phase reactant. Clin. Exp. Immunol., 17: 25 (1975).

22. Soothill, J. F. and Harvey, B. A. M.: Defective opsonisation. A common immunity deficiency. Arch. Dis. Child., 51: 90 (1976).

23. Soothill, J. F. and Harvey, B. A. M.: A Defect in the alternative pathway of complement. Clin. Exp. Immunol., 27: 30 (1977).

24. Strunk, R. C., Fenton, L. J., and Games, J. A.: Alternative pathway of complement activation in full term and premature infants. Pediatr. Res., 13: 641 (1979).

25. Thomas, H. C., deVilliers, D., Potter, B., Hodgson, H., Jain, S., Jewell, D. P., and Sherlock, S.: Immune complexes in acute and chronic liver disease. Clin. Exp. Immunol., 31: 150 (1978).

26. Thomas, H. C., Potter, B. J., Elias, E., Sherlock, S.: Metabolism of the third complement in acute Type B hepatitis, HBs antigen-positive glomerulonephritis, polyarthritis nodosum and HBs antigen positive and chronic active liver disease. Gastroenterology, 76: 673 (1979).

27. Wilkinson, S. P., Aroyo, V., Gazzard, B. G., Moodie, H., and Williams, R. Relation of renal impairment and haemorrhagic diathesis to endotoxaemia in fulminant hepatic failure. Lancet, $1: 521$ (1974).

28. Wyke, R. J., Rajkovic, I. A., Eddleston, A. W. L. F., and Williams, R.: Defective opsonisation of complement deficiency in sera from patients with fulminant hepatic failure. Gut, 21: 643 (1980).

29. Wyke, R. J., Canalese, J., Gimson, A. E. S., and Williams, R.: Bacteraemia in patients with fulminant hepatic failure. Liver (International), 2: 45 (1982).

30. Requests for reprints should be addressed to: Dr. V. F. Larcher, Department of Child Health, King's College Hospital, Denmark Hill, London, SE5 8RX Great Britain.

31. Received for publication March 25, 1982.

32. Accepted for publication August 25, 1982 